\title{
SLAM-Family Receptors: Immune Regulators with or without SAP-Family Adaptors
}

\author{
André Veillette ${ }^{1,2,3}$ \\ ${ }^{1}$ From the Laboratory of Molecular Oncology, Clinical Research Institute of Montréal, Montréal, \\ Québec, Canada \\ ${ }^{2}$ Department of Medicine, University of Montréal, Montréal, Québec, Canada \\ ${ }^{3}$ Department of Medicine, McGill University, Montréal, Québec, Canada \\ Correspondence: veillea@ircm.qc.ca
}

\begin{abstract}
The signaling lymphocytic activation molecule (SLAM) family of receptors and the SLAMassociated protein (SAP) family of intracellular adaptors are expressed in immune cells. By way of their cytoplasmic domain, SLAM-related receptors physically associate with SAP-related adaptors. Evidence is accumulating that the SLAM and SAP families play crucial roles in multiple immune cell types. Moreover, the prototype of the SAP family, that is SAP, is mutated in a human immunodeficiency, X-linked lymphoproliferative (XLP) disease. In the presence of SAP-family adaptors, the SLAM family usually mediates stimulatory signals that promote immune cell activation or differentiation. In the absence of SAP-family adaptors, though, the SLAM family undergoes a "switch-of-function," thereby mediating inhibitory signals that suppress immune cell functions. The molecular basis and significance of this mechanism are discussed herein.
\end{abstract}

mmune cells undergo differentiation and, once mature, are activated through the integrated actions of many molecules, including cell surface receptors and intracellular signaling effectors. Whereas some of these molecules have "primary" roles in the immune response, others have secondary, albeit still critical, functions in this process. For example, differentiation and activation of $\mathrm{B}$ cells are strictly dependent on the function of the B-cell receptor (BCR) and its intracellular effectors. Other receptors present on B cells, such as CD19 and CD40, influence B-cell functions in critical ways, by modulating BCR-triggered signals (Cambier et al. 1994).

There is accumulating evidence that the signaling lymphocytic activation molecule (SLAM) family of receptors plays important roles in immunity (Schwartzberg et al. 2009; Ma et al. 2007; Veillette et al. 2007; Veillette 2006b; Veillette 2006a). This class of receptors provides key effects in multiple immune cell types. Recent data indicate that SLAM-family receptors can either promote or inhibit the functions of primary activating receptors (CruzMunoz et al. 2009; Dong et al. 2009). These

Editors: Lawrence E. Samelson and Andrey Shaw

Additional Perspectives on Immunoreceptor Signaling available at www.cshperspectives.org

Copyright (C) 2010 Cold Spring Harbor Laboratory Press; all rights reserved; doi: 10.1101/cshperspect.a002469

Cite this article as Cold Spring Harb Perspect Biol 2010;2:a002469 
A. Veillette

alternative activities are controlled by whether or not SLAM-related receptors are coexpressed with members of the SLAM-associated protein (SAP) family of intracellular adaptor molecules. The functions and mechanisms of action of the SLAM and SAP families are reviewed herein.

\section{THE SLAM-FAMILY OF RECEPTORS}

\section{Properties}

The SLAM family of receptors is a group of type I transmembrane receptors that includes SLAM (CD150; SLAMF1), 2B4 (CD244; SLAMF4), Ly-9 (CD229; SLAMF3), natural killer, T- and B-cell antigen (NTB-A) or Ly108 (in the mouse) (SLAMF6), CD84 (SLAMF5), and $\mathrm{CD} 2$-like receptor activating cytotoxic cells (CRACC; CD319; and SLAMF7) (Table 1) (Schwartzberg et al. 2009; Ma et al. 2007; Veillette et al. 2007; Veillette 2006b; Veillette 2006a). SLAM-family receptors are broadly expressed in immune cells, and are not found in nonimmune cells. They possess an extracellular segment usually composed of two immunoglobulin (Ig)-like domains-one variable (V)-like domain and one constant 2 (C2)-like domain - in addition to a transmembrane region and a cytoplasmic domain bearing multiple tyrosine-based motifs. The one exception to this structural organization is Ly-9, which has four Ig-like domains in its extracellular domain (two tandem repeats of the basic V-like and C2-like organization).

One of the distinguishing features of SLAMfamily members is that, unlike most other receptors expressed in immune cells, SLAMrelated receptors are typically self-ligands. There is only one exception to this property, that is 2B4, which interacts with CD48, another Ig superfamily member found on nearly all hematopoietic cells (Latchman et al. 1998; Brown et al. 1998). Thus, SLAM-family receptors can be triggered in the context of homotypic or heterotypic cell-cell interactions (Fig. 1). SLAM is also the receptor for a variety of morbilliviruses (Tatsuo et al. 2000). These include measles virus, which binds and enters immune cells via SLAM in humans. In all cases examined by crystallography (NTB-A, 2B4, and CD84), the association of SLAM-family receptors with their physiological ligand was observed to be mediated via the amino-terminal V-like domain (Cao et al. 2006; Velikovsky et al. 2007; Yan et al. 2007).

Table 1. SLAM-family receptors

\begin{tabular}{|c|c|c|c|c|c|c|}
\hline \multirow[b]{2}{*}{ Receptor } & \multirow[b]{2}{*}{$\begin{array}{c}\text { Physiological } \\
\text { ligand }\end{array}$} & \multirow[b]{2}{*}{ Expression pattern } & \multicolumn{2}{|c|}{$\begin{array}{c}\text { Interaction } \\
\text { with }\end{array}$} & \multirow[b]{2}{*}{$\begin{array}{l}\text { Phenotypes } \\
\text { knockout mice }\end{array}$} & \multirow{2}{*}{$\begin{array}{c}\text { Genetic } \\
\text { background } \\
\text { knockout mice }\end{array}$} \\
\hline & & & SAP & $\begin{array}{l}\text { EAT-2 } \\
\text { (ERT) }\end{array}$ & & \\
\hline $\begin{array}{l}\text { SLAM } \\
\qquad \text { (SLAMF1) }\end{array}$ & SLAM & T, B, DC, M $\varphi$, plat. & + & + & $\begin{array}{l}\mathrm{T}, \mathrm{M} \varphi \text {, plat., NK-T } \\
\text { (with Ly108) }\end{array}$ & mixed 129-B6 \\
\hline 2B4 (SLAMF4) & CD48 & $\begin{array}{l}\mathrm{NK}, \mathrm{T}\left(\mathrm{CD}^{+}\right), \mathrm{DC}, \\
\mathrm{M} \varphi \text {, eos. }\end{array}$ & + & + & NK & pure B6 \\
\hline $\begin{array}{l}\text { NTB-A/Ly108 } \\
\text { (SLAMF6) }\end{array}$ & NTB-A/Ly108 & $\begin{array}{l}\text { T, B, NK, DC, } \\
\text { neutro. }\end{array}$ & + & + & T, neutro., NK-T & mixed 129-B6 \\
\hline $\begin{array}{l}\text { Ly-9 } \\
\quad \text { (SLAMF3) }\end{array}$ & Ly-9 & $\mathrm{T}, \mathrm{B}, \mathrm{NK}, \mathrm{DC}, \mathrm{M} \varphi$ & + & + & $\mathrm{T}$ & mixed 129-B6 \\
\hline $\begin{array}{l}\text { CD84 } \\
\quad \text { (SLAMF5) }\end{array}$ & CD84 & $\begin{array}{l}\mathrm{T}, \mathrm{B}, \mathrm{NK}, \mathrm{DC}, \mathrm{M} \varphi \\
\text { plat., mast, eos. }\end{array}$ & + & + & Not reported & Not reported \\
\hline $\begin{array}{l}\text { CRACC } \\
\text { (SLAMF7) }\end{array}$ & CRACC & $\begin{array}{c}\mathrm{T} \text { (activated), B, } \\
\mathrm{NK}, \mathrm{DC}, \mathrm{M} \varphi\end{array}$ & - & + & NK & pure 129 \\
\hline
\end{tabular}

The salient features of SLAM-family receptors are depicted. T, T cells; B, B cells; DC, dendritic cells, M $\phi$, macrophages; plat., platelets; NK, natural killer cells; eos., eosinophils; neutro., neutrophils; mast, mast cells; NK-T, natural killer-T cells; B6, C57BL/6. 
SLAM-Family Receptors: Immune Regulators with or without SAP-Family Adaptors

A

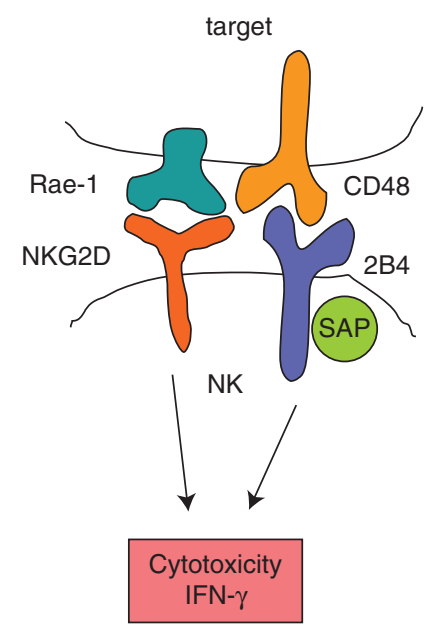

B Homotypic

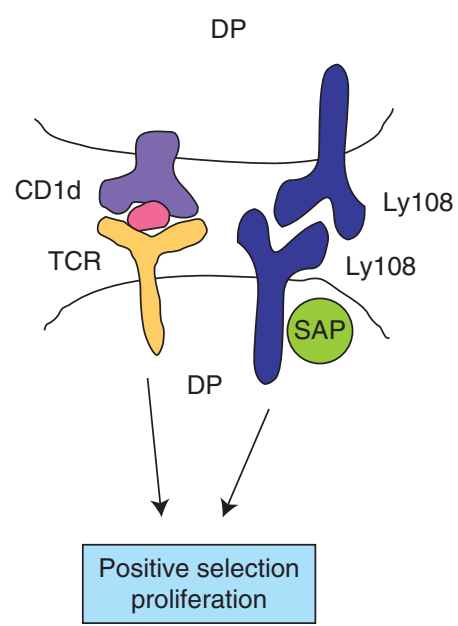

Figure 1. Triggering of SLAM-family receptors by heterotypic or homotypic cell-cell interactions. All SLAM-family receptors, except 2B4, are self-ligands. In the case of 2B4, the ligand is CD48, another receptor expressed on hematopoietic cells. Consequently, SLAM-family receptors can be triggered during heterotypic or homotypic cell-cell interactions. (A) Heterotypic cell-cell interactions. Triggering of 2B4 on natural killer cells (NK) by CD48 on target cells results in SAP family adaptor-dependent signals, which enhance cytotoxicity and interferon (IFN) $-\gamma$ secretion induced through stimulation of the primary activating receptor NKG2D by its ligand Rae-1. (B) Homotypic cell-cell interactions. Triggering of Ly108 by Ly108 on two double-positive thymocytes (DP) results in SAP-dependent signals, which promote positive selection and/or proliferation of DP expressing the appropriate T cell receptor (TCR) and engaged by self-lipid-loaded CD1d.

The genes coding from SLAM-family receptors are located within a $\sim 400$ kilobase $(\mathrm{kb})$ cluster on chromosome 1, in humans and mice (Morra et al. 2001). This observation, coupled with the conserved exon-intron structure of SLAM-related genes, implies that the SLAM family was generated by sequential duplication of a single ancestor gene. Sequence polymorphisms were documented in multiple members of the SLAM family. In some cases, these polymorphisms alter protein sequence. Interestingly, polymorphisms of SLAM-family genes among mouse strains, in particular of the Ly108-encoding gene, were found to correlate with susceptibility to the auto-immune disease systemic lupus erythematosus (SLE) (Wandstrat et al. 2004). Likewise, variations in the Ly-9- and 2B4-encoding genes were linked to susceptibility to SLE and rheumatoid arthritis (RA), respectively, in humans (Cunninghame Graham et al. 2008; Suzuki et al. 2008).

\section{Functions of SLAM-family Receptors}

Several lines of evidence support the notion that SLAM-family receptors carry out important functions in immune cells (Schwartzberg et al. 2009; Ma et al. 2007; Veillette et al. 2007; Veillette 2006b; Veillette 2006a). These include antibody stimulation experiments, studies in which SLAM-family receptors or their ligands are ectopically expressed on immune cells or target cells, genetic linkage analyses, and the creation of genetically modified mouse strains. In addition, SLAM-family receptors physically associate with SAP-family adaptors, which have been firmly implicated in normal immunity.

\section{Antibody Stimulation Experiments}

The first indication that the SLAM family is involved in immune regulation was provided for 2B4 (Garni-Wagner et al. 1993). It was 
A. Veillette

noted that a monoclonal antibody directed against mouse $2 \mathrm{~B} 4$ was able to stimulate cytotoxicity and interferon (IFN)- $\gamma$ secretion by lymphokine-activated killer (LAK) cells. It also promoted that ability of some $\mathrm{T}$ cells to mediate nonmajor histocompatibility complex (MHC)-restricted killing of target cells. Similar effects were later seen with antibodies directed against human 2B4, as well as human NTBA and CRACC, on natural killer (NK) cells (Nakajima et al. 1999; Bottino et al. 2001; Bouchon et al. 2001). Thus, these findings suggested that 2B4, NTB-A, and CRACC are activating receptors in NK cells and $\mathrm{T}$ cells.

Subsequently, it was reported that antibodymediated engagement of SLAM potentiated the proliferation of human $\mathrm{B}$ cells in response to interleukin-4 (IL-4) and anti-CD40 (Sidorenko and Clark 1993). Another group also showed that stimulation of previously activated human $\mathrm{T}$ cells ( T-cell blasts) or human T-cell clones by a monoclonal antibody against SLAM was able to induce production of IFN- $\gamma$, but not IL-4, even in the absence of concomitant engagement of the T-cell receptor (TCR) (Cocks et al. 1995). A similar antibody raised against mouse SLAM augmented IFN- $\gamma$ production by mouse $\mathrm{T}$ cells stimulated by $\mathrm{CD} 3$-specific monoclonal antibodies (Castro et al. 1999). However, unlike human $\mathrm{T}$ cells, activation of mouse $\mathrm{T}$ cells by anti-SLAM antibodies did not occur in the absence of TCR coengagement. In other studies, antibody-mediated ligation of SLAM was shown to promote cytotoxicity by $\mathrm{CD}^{+}$ $\mathrm{T}$ cells, secretion of IL- 12 and IL- 8 by dendritic cells (DCs), and production of IL-12 by macrophages (Wang et al. 2004; Henning et al. 2001; Rethi et al. 2006; Bleharski et al. 2001; Kruse et al. 2001). Collectively, these data hinted that SLAM is a positive regulator of activation of T cells, B cells, DCs, and macrophages.

\section{Ectopic Expression Studies}

Further substantiation of the regulatory activity of SLAM-related receptors was obtained through studies in which ligands for SLAM-family receptors are ectopically expressed on targets for NK cells. Several groups reported that expression of CD48, the ligand of 2B4, on target cells enhanced the cytotoxicity mediated by human NK cells (Nakajima et al. 1999). This effect was subsequently extended to NTB-A, CRACC, and, at least in the mouse, Ly-9 (Bottino et al. 2001; Bouchon et al. 2001; Dong et al. 2009). Yet other studies raised the possibility that, in the mouse, 2B4 may carry out an inhibitory function in NK cells. Indeed, two groups found that expression of CD48 on target cells inhibited, rather than enhanced, mouse NK-cell functions (Lee et al. 2004; Mooney et al. 2004). Nonetheless, two additional laboratories found that expression of CD48 on targets augmented mouse NK-cell cytotoxicity (Dong et al. 2009; Bloch-Queyrat et al. 2005). Although the basis for this disparity is not clarified, these observations nonetheless supported the idea that $2 \mathrm{~B} 4$ regulates NK-cell functions.

Other data also suggested that 2B4, as well as other SLAM-related receptors, can inhibit immune cell functions in some settings. Chief among these was the finding that expression of CD48 on targets inhibited the ability of normal immature or uterine human NK cells to mediate killing (Vacca et al. 2006; Sivori et al. 2002). Likewise, expression of CD84 on the rat basophilic leukemia cell line RBL-2H3 suppressed IgE-mediated degranulation (Oliver-Vila et al. 2008). Furthermore, expression of CRACC on a fibroblast cell line bearing class II MHC molecules inhibited antigen-triggered activation of mouse T cells (Cruz-Munoz et al. 2009).

Hence, in combination, these findings raised the possibility that SLAM-family receptors have pleiotropic effects in immune cells, and that they can be at times activating and at times inhibitory.

\section{Genetic Linkage Analyses}

Genetic data cemented the proposal that SLAMfamily receptors have pivotal roles in immune regulation. It was found that the Sle1b locus, which confers enhanced susceptibility to SLE in mouse strains such as NZM2410 and 129Sv compared with C57BL/6, corresponds to the Slam-family locus on mouse chromosome 1 
(Wandstrat et al. 2004). Polymorphisms in the gene encoding Ly108 were found to correlate most robustly with disease susceptibility, although the genes coding for other members of the SLAM family (in particular Ly-9) may also participate. These polymorphisms were reported to regulate lupus susceptibility by altering T-cell and B-cell functions (Kumar et al. 2006; Wandstrat et al. 2004).

Likewise, the Nkt1 locus, which influences NK-T cell numbers and functions in autoimmune nonobese diabetes (NOD) mice, was also observed to correspond to the Slam locus (Jordan et al. 2007). In particular, the genes coding for SLAM and Ly108 were identified as likely susceptibility genes. The Nkt1 locus in NOD mice was shown to result in reduced SLAM expression on double-positive thymocytes, possibly explaining the reduced NK-T cell numbers in these animals.

Lastly, in humans, a polymorphism in the gene coding for 2B4 was reported to increase the susceptibility to rheumatoid arthritis in a Japanese population (Suzuki et al. 2008). Moreover, a polymorphism in the gene encoding Ly-9 affected susceptibility to familial SLE in Canada and the United Kingdom (Cunninghame Graham et al. 2008). It also influenced the representation of $\mathrm{CD}^{+}$and $\mathrm{CD} 4^{+} \mathrm{T}$-cell subsets.

Combined, these observations provided strong correlative evidence that, through sequence variations that affect protein function or expression, SLAM-related genes are implicated in the pathophysiology of auto-immune diseases in humans and mice.

\section{Analyses of Genetically Modified Mice}

A major limitation of antibody stimulation experiments and overexpression studies is that these manipulations can evoke nonphysiological effects. There are many examples highlighting this caveat. Similarly, genetic linkage analyses provide only correlative evidence of involvement of gene products in a function. For these reasons, studies of genetically modified mice are crucial for formally determining the physiological activities of molecules, although conventional gene ablation approaches do not address well the possibilities of functional redundancy and compensation by other molecules.

Mutant mice were engineered for several SLAM-family receptors (Table 1). Mice lacking SLAM were found to show a defect in TCRmediated IL-4 secretion (Wang et al. 2004; Davidson et al. 2004). Moreover, their macrophages had altered production of IL-12, tumor necrosis factor- $\alpha$ (TNF- $\alpha$ ), IL-6, and nitric oxide (NO) in response to lipopolysaccharide (LPS). Lastly, SLAM-deficient platelets showed defective aggregation in response to collagen or thrombin receptor stimulation (Nanda et al. 2005).

2B4-deficient mice were observed to have a complex NK-cell phenotype, which was not expected from the earlier antibody stimulation experiments (Vaidya et al. 2005; McNerney et al. 2005; Lee et al. 2004). NK cells lacking 2B4 had augmented, instead of diminished, cytotoxicity toward target cells. Intriguingly, this effect was restricted to target cells expressing CD48. In contrast, an enhancement of cytotoxicity was seen with target cells lacking CD48. Whereas these genetic data undoubtedly implicated 2B4 in the regulation of NK-cell-mediated cytotoxicity, they also implied that 2B4-CD48 interactions can have two types of effect. Seemingly, 2B4 is inhibitory when engaged by CD48 located on target cells. However, it becomes activating when triggered by CD48 on other NK cells. Additional evaluations are needed to explain these findings, especially in the context of the other data indicating that 2B4 is primarily an activating receptor in NK cells.

Mice devoid of CRACC were also found to have an NK-cell defect (Cruz-Munoz et al. 2009). CRACC-deficient NK cells had a compromised ability to kill and produce IFN- $\gamma$ in response to target cells expressing CRACC, in keeping with the notion that CRACC is a self-ligand. Interestingly, their aptitude to react to CRACC-negative targets was also reduced, although not as severely as the response to CRACC-positive targets. Hence, it would appear that CRACC-CRACC interactions promote NK-cell activation in the context of heterotypic 
A. Veillette

NK-cell-target-cell interactions and homotypic NK-cell-NK-cell interactions.

Ly108-deficient mice were observed to have a defect in TCR-mediated IL-4 secretion and compromised neutrophil bactericidal activity (Howie et al. 2005). Likewise, they showed reduced NK-T cell development, which was further compromised by combining Ly108 deficiency with SLAM deficiency (Griewank et al. 2007). The effect of Ly108 and SLAM deficiency on NK-T cell development was reported to be caused by compromised homotypic interactions among double-positive thymocytes, which contain the precursors of NK-T cells. Last, mice with a mutation of the Ly-9-encoding gene had compromised TCR-induced proliferation and IL-2 secretion (Graham et al. 2006).

These gene ablation experiments provided the best direct indication of the importance of the SLAM family in immune regulation. Moreover, they exemplified the idea that the functions of SLAM-family receptors can be triggered by heterotypic or homotypic interactions among immune cells. However, it is noteworthy that these data also failed to confirm several of the functions of SLAM-family receptors expected based on antibody stimulation experiments. This situation offers one additional example that the results of antibody stimulation experiments need to be interpreted with caution, as antibodies can be agonistic or antagonistic, or, at times, trigger nonphysiological effects.

Nonetheless, there are also some caveats to the gene ablation experiments. First, they may underestimate the functions of individual SLAM-family receptors. This is especially important for SLAM-family receptors because a given immune cell type typically expresses multiple family members. For example, $\mathrm{T}$ cells express SLAM, NTB-A, Ly-9, CD84, and, occasionally, CRACC and 2B4. Likewise, NK cells bear 2B4, NTB-A, CRACC, Ly-9, and CD84. The creation of mice simultaneously carrying mutations in multiple SLAM-family members will be critical to ascertain this possibility, although it is technically complicated by the close juxtaposition of Slam-related genes on mouse chromosome 1.
Second, it is possible that variations in genetic background underlie or mask some of the phenotypes observed in gene-ablated mice (Veillette et al. 2006). As pointed out earlier, in the mouse, the Slam locus corresponds to the Sle $1 b$ and Nkt1 loci, which confer enhanced susceptibility to autoimmunity and are associated with altered T-cell and B-cell functions. The Slam locus is known to show marked structural and functional differences between C57BL/ 6 and 129Sv mice (Wandstrat et al. 2004). As the various genes of the Slam locus cosegregate during genomic recombination, it is plausible that some of the phenotypes observed in mutant mice analyzed in a mixed C57BL/6-129Sv background were caused by, or were masked by, transfer of the Slam locus from 129Sv to C57BL/6. Mice with a mixed background were used for mutations of SLAM, Ly108, and Ly-9 (Howie et al. 2005; Wang et al. 2004; Davidson et al. 2004; Graham et al. 2006). In the light of this, it will be important to confirm the phenotypes, or lack of phenotypes, in the mutant animals using a pure genetic background.

\section{Interactions with SAP-family adaptors}

The most striking, albeit only indirect, substantiation of the involvement of SLAM-family receptors in immunity was the finding that they associate with SAP-family adaptors (Schwartzberg et al. 2009; Ma et al. 2007; Veillette et al. 2007; Veillette 2006b; Veillette 2006a). The prototype of the SAP family, that is SAP, is mutated in a human immunodeficiency, X-linked lymphoproliferative (XLP) disease. Moreover, mice lacking one or more members of the SAP family have marked immune phenotypes. Thus, such findings further implicated the SLAM family in immune regulation. The SAP family will now be reviewed.

\section{THE SAP FAMILY OF ADAPTORS}

\section{Properties}

The SAP family of adaptors includes three members most commonly known as SAP (also 
SLAM-Family Receptors: Immune Regulators with or without SAP-Family Adaptors

Table 2. SAP-family adaptors.

\begin{tabular}{|c|c|c|c|c|c|c|}
\hline Adaptor & $\begin{array}{c}\text { Chromosomal } \\
\text { localization }\end{array}$ & $\begin{array}{c}\text { Expression } \\
\text { pattern }\end{array}$ & $\begin{array}{c}\text { Signaling } \\
\text { mechanism }\end{array}$ & $\begin{array}{c}\text { Phenotypes } \\
\text { knockout mice }\end{array}$ & $\begin{array}{c}\text { Genetic } \\
\text { background } \\
\text { knockout } \\
\text { mice } \\
\end{array}$ & $\begin{array}{l}\text { Human } \\
\text { disease } \\
\end{array}$ \\
\hline $\begin{array}{l}\text { SAP } \\
\qquad(\mathrm{SH} 2 \mathrm{D} 1 \mathrm{~A})\end{array}$ & $\mathrm{X}(\mathrm{H}, \mathrm{M})$ & $\begin{array}{l}\text { T, ?B, NK-T, } \\
\text { NK, plat. }\end{array}$ & $\begin{array}{l}\text { Fyn, ?PIX, } \\
\text { ?Nck } \\
\text { (arginine } \\
78 \text { ) }\end{array}$ & $\begin{array}{l}\mathrm{T}_{\mathrm{H}} 2, \mathrm{~T}_{\mathrm{FH}}, \mathrm{B} \\
\text { (?indirect), } \\
\text { NK-T, NK, } \\
\text { plat. }\end{array}$ & $\begin{array}{l}\text { Mixed } \\
129-\mathrm{B} 6\end{array}$ & XLP \\
\hline $\begin{array}{l}\text { EAT-2 } \\
\qquad(\mathrm{SH} 2 \mathrm{D} 1 \mathrm{~B} 1)\end{array}$ & $1(\mathrm{H}, \mathrm{M})$ & $\mathrm{NK}, \mathrm{DC}, \mathrm{M} \varphi$ & $\begin{array}{l}\text { ?PLC- } \gamma 1 \\
\text { (carboxy- } \\
\text { terminal } \\
\text { tyrosines) }\end{array}$ & NK & 129 & none \\
\hline $\begin{array}{l}\text { ERT } \\
\qquad(\mathrm{SH} 2 \mathrm{D} 1 \mathrm{~B} 2)\end{array}$ & $\begin{array}{l}1 \mathrm{H}, \mathrm{M} ; \\
\quad \text { pseudo- } \\
\quad \text { gene in } \mathrm{H})\end{array}$ & NK & $\begin{array}{l}\text { (?carboxy- } \\
\text { terminal } \\
\text { tyrosines) }\end{array}$ & NK & 129 & none \\
\hline
\end{tabular}

The salient features of SAP-family adaptors are depicted. $\mathrm{H}$, human; $\mathrm{M}$, mouse; T, T cells; B, B cells; NK-T, natural killer-T cells; NK, natural killer cells; plat., platelets; DC, dendritic cells, $M \varphi$, macrophages; PLC, phospholipase C; C, carboxyl; $\mathrm{T}_{\mathrm{H}} 2$, $\mathrm{T}$ helper 2 cells; $\mathrm{T}_{\mathrm{FH}}$, follicular helper T cells; B6, C57BL/6; XLP, X-linked lymphoproliferative disease.

named SH2D1A), Ewing's sarcoma-associated transcript-2 (EAT-2; also named SH2D1B1), and EAT-2-related transducer (ERT; also named SH2D1B2) (Table 2) (Schwartzberg et al. 2009; $\mathrm{Ma}$ et al. 2007; Veillette et al. 2007; Veillette 2006b; Veillette 2006a). These intracellular molecules are composed of a Src homology 2 (SH2) domain, in addition to a short carboxy-terminal region. They appear to be solely expressed in immune cells. Although SAP is present in T cells, NK cells, NK-T cells, and, perhaps, some B cells, EAT-2 is found in NK cells, DCs, and macrophages. ERT is only observed in NK cells, at least in the mouse. The SAP-encoding gene is located on the $\mathrm{X}$ chromosome in humans and mice. In contrast, the genes coding for EAT-2 and ERT are positioned in tandem on chromosome 1, in the two species (Calpe et al. 2006). They are located approximately $1500 \mathrm{~kb}$ and $1300 \mathrm{~kb}$ away from the SLAM locus in humans and mice, respectively. In humans, the ERT-encoding gene is a pseudogene and is nonfunctional.

Through their SH2 domain, SAP-family adaptors associate with the tyrosine-based motif $\mathrm{TI} / \mathrm{VYxxV} / \mathrm{I}$ (in which $\mathrm{T}$ is threonine, $\mathrm{I}$ is isoleucine, $\mathrm{V}$ is valine, $\mathrm{Y}$ is tyrosine and $\mathrm{x}$ is any residue) in the cytoplasmic domain of SLAM-related receptors (Sayos et al. 1998;
Schwartzberg et al. 2009; Ma et al. 2007; Veillette et al. 2007; Veillette 2006b; Veillette 2006a). These interactions are of high affinity and specificity. Current evidence suggests that all SAPfamily adaptors can interact with all SLAMfamily receptors, with the clear exception of CRACC that associates with EAT-2 and presumably ERT, but not SAP (Tassi and Colonna 2005; Bouchon et al. 2001; Cruz-Munoz et al. 2009). Compared with other $\mathrm{SH} 2$ domain-mediated associations, the interactions between SAPrelated adaptors and SLAM-family receptors have unusual structural characteristics. These properties and their potential significance are reviewed elsewhere (Schwartzberg et al. 2009; $\mathrm{Ma}$ et al. 2007; Veillette et al. 2007; Veillette 2006b; Veillette 2006a).

\section{SAP is Mutated in X-Linked Lymphoproliferative Disease}

The SAP-encoding gene ( $S H 2 D 1 A)$ is mutated in $60 \%-70 \%$ of cases of XLP, an X-linked human immunodeficiency characterized by a disproportionate and ineffective response to Epstein-Barr virus (EBV) infection (Coffey et al. 1998; Sayos et al. 1998; Nichols et al. 1998). All SAP mutations found in XLP are null mutations or loss-of-function mutations. 
A. Veillette

Although readers are referred elsewhere for indepth discussions of the clinical and immunological features of XLP (Schwartzberg et al. 2009; Ma et al. 2007; Veillette et al. 2007; Veillette 2006b; Veillette 2006a), it is worth mentioning that, on EBV infection, SAP-deficient patients typically show a massive lymphoproliferative illness, with marked accumulation of immune cells in lymphoid and nonlymphoid tissues. They also have a heightened frequency of malignant lymphomas. Moreover, at the immunological level, they show defects in the functions or development of several immune cell types, including $\mathrm{CD} 4^{+} \mathrm{T}$ cells, $\mathrm{CD} 8^{+} \mathrm{T}$ cells, NK-T cells, B cells, and NK cells (Table 2). It is believed that, combined, these alterations explain the abnormal immune response to EBV.

Mutations in genes other than SH2D1A were recently identified in some patients with XLP or XLP-like illnesses. The gene encoding the X-linked inhibitor of apoptosis (XIAP) was found to be mutated in $5 \%-10 \%$ of cases of XLP (Rigaud et al. 2006). Furthermore, one group observed that the protein tyrosine kinase (PTK) Itk was mutated in two female relatives having an XLP-like immunodeficiency (Huck et al. 2009). Whether or not XIAP and Itk are part of a common signaling pathway with SAP remains to be elucidated.

\section{Immune Defects in Mice Lacking SAP-family} Adaptors

The involvement of SAP-family adaptors in immune regulation was also shown by the generation of mice carrying inactivating mutations in their genes (Table 2). Mutations of the SAP-encoding gene largely recreated the phenotypes of SAP-deficient humans (Schwartzberg et al. 2009; Ma et al. 2007; Veillette et al. 2007; Veillette 2006b; Veillette 2006a). Defects in $\mathrm{CD}^{+}{ }^{+} \mathrm{T}$-cell functions, including reduced $\mathrm{T}$ helper $2\left(\mathrm{~T}_{\mathrm{H}} 2\right)$ cytokine production and defective follicular T-helper $\left(\mathrm{T}_{\mathrm{FH}}\right)$ cell functions, were observed. This $\mathrm{T}_{\mathrm{FH}}$ defect leads to severely compromised germinal center formation and antibody production by $\mathrm{B}$ cells, although a $\mathrm{T}$ cell-independent intrinsic B-cell defect may coexist (Veillette et al. 2008; Qi et al. 2008;
Cannons et al. 2006). Alterations of CD8 ${ }^{+} \mathrm{T}$ cells, including reduced cytotoxicity and impaired activation-induced cell death, were also noted (Chen et al. 2007; Chen et al. 2005). Moreover, a near absence of NK-T cells, caused by an early block in NK-T cell development, was found (Chung et al. 2005; Nichols et al. 2005; Pasquier et al. 2005). Likewise, reduced NK-cell-mediated cytotoxicity and IFN- $\gamma$ secretion were observed (Dong et al. 2009; Bloch-Queyrat et al. 2005).

Mice lacking EAT-2 or ERT were shown to show complex alterations in NK-cell functions (Roncagalli et al. 2005). Unexpectedly, an increase, rather than a decrease, in cytotoxicity and IFN- $\gamma$ production was observed in response to stimulation of various activating receptors. This finding suggested that EAT-2 and ERT are negative regulators of NK-cell activation. However, other analyses, including studies of CRACC, which binds EAT-2 but not SAP, indicated that EAT-2 and ERT can also be positive regulators of NK-cell activation (Cruz-Munoz et al. 2009). Although the basis for this dual activity still needs to be clarified, it appears that EAT-2 (and ERT) are activating when SLAMfamily receptors are triggered as part of the NK-cell stimulation by target cells (Dong et al. 2009). In contrast, they are inhibitory when SLAM-family receptors are not triggered by target cells.

Recently, mice simultaneously lacking all three SAP-family adaptors were reported (Dong et al. 2009). It was observed that NK cells devoid of all SAP-family adaptors had much more severely compromised NK-cell functions than mice lacking individual SAP-family adaptors. This observation implied that the three members of the SAP family cooperate in a mechanism promoting NK-cell activation. Interestingly, NK cells lacking all SAP-family adaptors had a nearly abolished capacity to mediate cytotoxicity and produce IFN- $\gamma$ in response to hematopoietic, but not nonhematopoietic, target cells. This was because of the fact that hematopoietic, but not nonhematopoietic, cells express ligands for SLAM-family receptors. As was reported for NK cells lacking EAT-2 or ERT alone, NK cells devoid of all SAP-related adaptors also showed enhanced, 
instead of diminished, activation in response to nonhematopoietic target cells.

Thus, studies of SAP-deficient humans and of mice lacking one or more SAP family members constituted undeniable evidence of the importance of these molecules in immune regulation. Because SAP-family adaptors interact primarily, if not exclusively, with SLAMfamily receptors, these analyses also helped to implicate SLAM-related receptors in normal immunity.

Signaling Mechanisms of SAP-Family Adaptors

Given that SAP-family adaptors are almost exclusively made of an $\mathrm{SH} 2$ domain, it was proposed at first that they may be "natural blockers" of associations with other $\mathrm{SH} 2$ domaincontaining molecules (Sayos et al. 1998). In keeping with this idea, it was observed that SAP and EAT-2 could prevent the binding of SLAM-family members to inhibitory signaling molecules such as SH2 domain-containing phosphatase (SHP)-2 and SHP-1, SH2 domaincontaining 5' inositol phosphatase (SHIP)-1 and Csk, both in vitro and in overexpression studies (Schwartzberg et al. 2009; Ma et al. 2007; Veillette et al. 2007; Veillette 2006b; Veillette 2006a). Such a mechanism was postulated to prohibit SLAM-family receptors from mediating inhibitory signals, thereby favoring cell activation. However, this model was not validated in experiments using normal immune cells.

Subsequent studies unraveled that SAPfamily adaptors possess sequences that can also couple them to specific biochemical signals (Fig. 2). SAP was found to associate with the Src-related PTK Fyn, by way of a short motif located within the SAP SH2 domain (Latour et al. 2003; Latour et al. 2001; Chan et al. 2003). This Fyn-binding motif is centered on SAP arginine 78 (R78), which binds directly to the Src homology 3 (SH3) region of Fyn. Such a sequence is not found in EAT-2 and ERT. Because the SAP-Fyn interaction occurs simultaneously with binding of SAP to SLAMfamily receptors, it permits SAP to link
SLAM-family receptors to protein tyrosine phosphorylation signals. This association appears to be critical for some, but not all, functions of SAP (Nunez-Cruz et al. 2008; Davidson et al. 2004; Cannons et al. 2004; Qi et al. 2008; Cannons et al. 2006). For instance, it is essential for the ability of SAP to promote $\mathrm{T}_{\mathrm{H}} 2$ cytokine production, but has little or no role in the aptitude of SAP to augment $\mathrm{T}_{\mathrm{FH}}$ functions. An intermediate requirement exists for NK-T cell development. It should be pointed out that, in addition to binding Fyn, the R78-based motif of SAP can interact with other SH3 domaincontaining proteins such as PAK-interacting exchange factor (PIX) and the adaptor Nck (Gu et al. 2006; Li et al. 2009). The physiological relevance of these other associations is not clarified.

EAT-2 and ERT harbor sites of tyrosine phosphorylation in their carboxy-terminal tail (Roncagalli et al. 2005). These sites are not present in SAP. Two tyrosines exist in mouse EAT-2 and ERT (tyrosines 120 and 127), whereas only one is located in human EAT-2 (tyrosine 127). These tyrosines are positioned in classical SH2 domain-binding motifs. Evidence is accumulating that the carboxy-terminal tyrosines are critical for the activating and inhibitory effects of EAT-2 (and presumably ERT) in NK cells (Roncagalli et al. 2005; Cruz-Munoz et al. 2009; Clarkson and Brown 2009). Although it is presumed that the phosphorylated tyrosines of EAT-2 and ERT enable to couple SLAMfamily receptors to other $\mathrm{SH} 2$ domain-containing downstream effectors, the identity of these effectors is not clearly established. Nonetheless, recent data suggested that phospholipase C (PLC) $-\gamma$ may be recruited to tyrosine 127 in human EAT-2 (Clarkson and Brown 2009).

Collectively, these observations implied that SAP, EAT-2, and ERT are active signaling molecules that couple SLAM-related receptors to specific biochemical signals, although the nature of these signals still needs to be fully elucidated. It is conceivable that, under certain circumstances, SAP-family adaptors also function by blocking the association of SLAM-related with other SH2 domain-containing molecules. However, as suggested in the next section, this 
A. Veillette

A

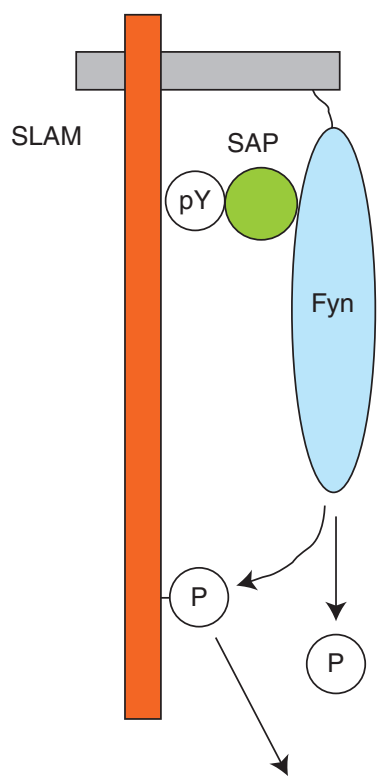

B

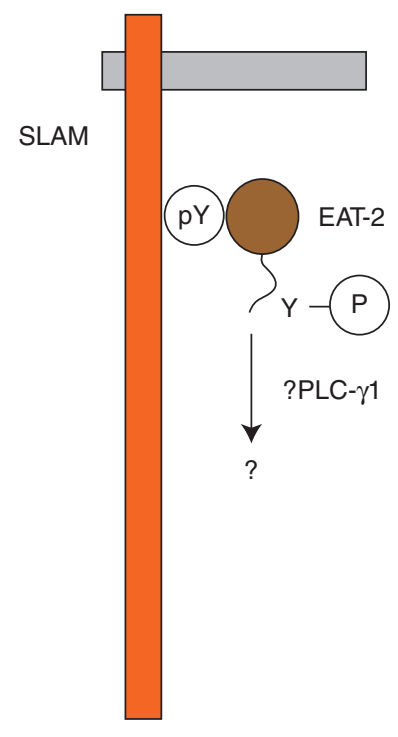

Figure 2. SAP-related adaptors mediate active biochemical signals. Through intrinsic mechanisms, SAP-family adaptors can couple SLAM-family receptors to active signals. (A) SAP. Via its Src homology 2 (SH2) region, SAP associates with a phosphorylated tyrosine-based motif ( $\mathrm{pY}$ ) in SLAM-related receptors (SLAM). By way of the arginine 78-based motif in its SH2 domain, SAP simultaneously binds to the Src family protein tyrosine kinase Fyn, through the Fyn Src homology 3 (SH3) domain. This allows SAP to couple SLAM-related receptors to protein tyrosine phosphorylation signals. (B) EAT-2. Like SAP, EAT-2 (and probably ERT; not shown) associates with a phosphorylated tyrosine-based motif ( $\mathrm{pY}$ ) in SLAM-related receptors (SLAM), through the EAT-2 SH2 domain. Via one or two phosphorylated tyrosines located in its carboxy-terminal tail, EAT-2 concomitantly interacts with its effectors. Although the identity of these effectors is not well defined, recent data suggested that phospholipase C (PLC) $-\gamma$ may be involved.

may not be through a classical natural blocker model.

\section{THE FUNCTIONS OF THE SLAM FAMILY ARE DEFINED BY THE PRESENCE OR THE ABSENCE OF THE SAP FAMILY}

\section{Differential Phenotypes of Deficiencies in SLAM Family or SAP Family}

Considering the specificity of the interaction between SLAM-family receptors and SAPfamily adaptors, it seems logical to speculate that SLAM-related receptors are responsible for the functions mediated by SAP-related adaptors. However, full acceptance of this notion has been hampered by the difficulty to recreate the severe phenotypes, which are caused by SAP family deficiencies, with mutations of the SLAM family. The one possible exception is the block of NK-T development caused by SAP deficiency that can be recapitulated to a considerable, albeit not full, extent by combined mutations of Ly108 and SLAM (Griewank et al. 2007).

Several possibilities may explain this discrepancy. First, as suggested earlier, it is likely that some functional redundancy exists between SLAM-family members. In this context, ablation of multiple members of the SLAM family may be needed to mimic the impact of SAP family deficiencies. Experiments to test this idea are underway in several laboratories. Second, it is possible that the functions of SLAMfamily receptors are qualitatively altered, rather than eliminated, by the absence of SAP-related 
adaptors. Consequently, there would be distinct phenotypes for SAP family deficiencies compared with SLAM-family deficiencies. Recent analyses of NK-cell functions in mice lacking all three SAP-family adaptors provided clear support for this proposition, as will be presented in the upcoming section. And third, it is conceivable that SAP-family adaptors also mediate SLAM family independent functions. Whereas this idea is supported by the finding of associations between SAP and receptors such as CD22 and FcyRIIB, the physiological relevance of these associations is not clear (Ostrakhovitch et al. 2009; Li et al. 2008). Nonetheless, this possibility still deserves consideration.

\section{"Switch-of-Function" of SLAM-Family Receptors in the Absence of the SAP Family}

Recently, it was found that, in the absence of all SAP-family adaptors, SLAM-family receptors on mouse NK cells, including 2B4, Ly108, CRACC, Ly-9, and CD84, not only lose their activating function, but also are converted into potent inhibitory receptors (Fig. 3) (Dong et al. 2009). This inhibitory activity enables SLAMfamily receptors to suppress the function of other activating NK-cell receptors such as natural-killer group 2, member D (NKG2D), CD16 and, probably, DNAX accessory molecule-1 (DNAM-1), thereby leading to a marked suppression of NK-cell responsiveness toward hematopoietic target cells. A related switch-offunction from activating to inhibitory was also described for 2B4 and NTB-A in SAP-deficient human NK cells (Bottino et al. 2001; Bottino et al. 2000). Likewise, it was noted for 2B4 in normal immature and uterine human NK cells, which express low amounts of SAP (Vacca et al. 2006; Sivori et al. 2002).

Taking into consideration these findings, it is tempting to speculate that other manifestations of SAP family deficiencies may also occur through a switch-of-function mechanism. In this manner, the $\mathrm{T}_{\mathrm{FH}}$ and $\mathrm{T}_{\mathrm{H}} 2$ defects, the block in NK-T cell development, and the $\mathrm{CD}^{+} \mathrm{T}$ cell dysfunctions caused by SAP deficiency may be
A

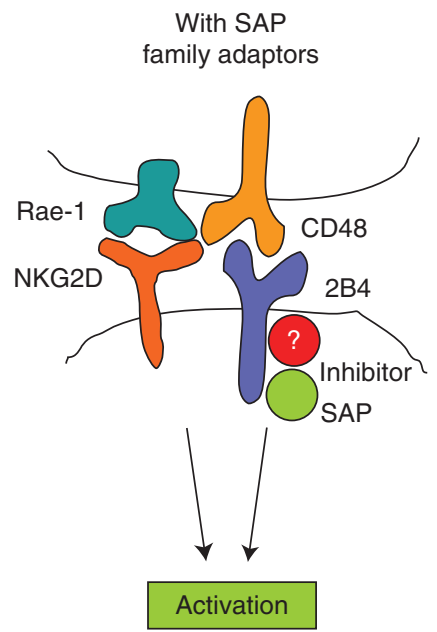

B

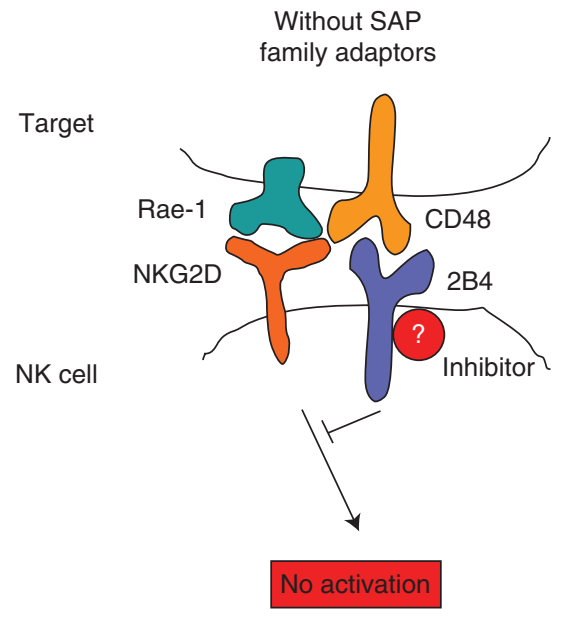

Figure 3. "Switch-of-function" of SLAM-family receptors in the absence of SAP-family adaptors. (A) In the presence of SAP-family adaptors, SLAM-family receptors (2B4 is depicted here) mediate positive signals that promote natural killer cell (NK) activation by target cells. This is because SAP family adaptor-mediated signals dominate over signals mediated by inhibitory effectors, which are proposed to bind a tyrosine-based motif distinct from the one interacting with SAP-related adaptors. $(B)$ In the absence of SAP-family adaptors, however, SLAM-family receptors mediate negative signals that inhibit natural killer cell (NK) activation by target cells. This is because inhibitory signals dominate. 
A. Veillette

due at least in part to a change, rather than a loss, in the function of SLAM-related receptors. A comparison of the phenotypes caused by the absence of the SAP family with those induced by simultaneous loss of all SLAM-related receptors will help address this possibility.

\section{Mechanism of Switch-of-Function by SAP-Family Adaptors}

A simple way to explain the switch-of-function of SLAM-related receptors in the absence of the SAP family is based on the natural-blocker model (Sayos et al. 1998). Accordingly, in the absence of SAP-related adaptors, SLAM-family receptors would preferentially associate with inhibitory effectors such as SHP-1, SHP-2, SHIP-1, or Csk, and, thereby, mediate inhibitory effects. Even though data in transfected cells supported this hypothesis, these findings were not substantiated by analyses in normal immune cells (Schwartzberg et al. 2009; Ma et al. 2007; Veillette et al. 2007; Veillette 2006b; Veillette 2006a).

Nonetheless, a recent report showed that, in the absence of SAP-family adaptors, triggering of 2B4 on mouse NK cells resulted in enhanced tyrosine phosphorylation of the inositol phosphatase SHIP-1 (Dong et al. 2009). This was accompanied by reduced activation of calcium fluxes, Erk, and Akt on coengagement of CD16. Because calcium fluxes, Erk and Akt are known to be inhibited by SHIP-1. Such findings implied that, in the absence of SAP-family adaptors, 2B4 and, possibly, other SLAM-related receptors are more efficiently coupled to inhibitory effectors like SHIP-1.

However, this phenomenon does not appear to reflect direct physical competition between SAP-family adaptors and inhibitory effectors for binding to SLAM-family receptors. Along these lines, studies in mouse NK cells showed that distinct tyrosines in the cytoplasmic domain of CRACC are responsible for CRACCmediated activation, which occurs in the presence of EAT-2, and for CRACC-mediated inhibition, which takes place in the absence of EAT-2 (Cruz-Munoz et al. 2009). This observation implied that SAP-family adaptors and inhibitory effectors do not compete for binding to the same tyrosine. Other models such as "functional competition," "trans-regulation," or "steric hindrance" should be considered, as detailed elsewhere (Veillette et al. 2009). Interestingly, these investigations also revealed that SHIP-1, SHP-1, SHP-2, and Csk did not bind directly to the tyrosine-based motif responsible for inhibition, suggesting that they are indirectly recruited to the inhibitory tyrosine.

Altogether, these data supported the view that SHIP-1 and, perhaps, SHP-1, SHP-2, and Csk, participate in the inhibition seen in the absence of SAP-family adaptors. Obviously, genetic data supporting this view remain to be obtained. Importantly, these results also indicated that the switch-of-function mediated by the SAP family is not simply because of direct competitive binding between SAP-related adaptors and inhibitory effectors to SLAM-related receptors. However, the mechanism responsible still needs to be elucidated.

\section{CONCLUSION}

The data reviewed herein provided clear evidence that the SLAM and SAP families play crucial roles in normal immunity. These functions take place in multiple cell types, including T cells, NK-T cells, B cells, NK cells, macrophages and, probably, others. Because most SLAM-family receptors have the unusual property of being self-ligands, these activities can be triggered by homotypic or heterotypic cell-cell interactions.

The findings obtained so far also unraveled that SAP-family adaptors enable SLAM-family receptors to mediate positive signals, which usually promote immune-cell activation and/ or differentiation. In the absence of SAP-family adaptors, however, SLAM-family receptors switch their function and mediate other signals, which are typically inhibitory in nature. Such effects are clearly observed in immune cells lacking SAP-family adaptors, as seen in cases of XLP in humans and in genetically engineered mutant mouse strains. Moreover, they may occur under physiological circumstances, in immune-cell types expressing little or no 
SAP-family adaptors, such as B cells, mast cells, and neutrophils (Veillette et al. 2009).

In summary, SLAM-family receptors are key regulators that can mediate opposite functions in immune cells. These functions are determined by the presence or the absence of SAP-family adaptors. Although the critical importance of the SLAM and SAP families in immune regulation has been undoubtedly established, much work still remains to be performed to understand fully the functions and mechanisms of action of these families in immunity.

\section{ACKNOWLEDGMENTS}

Work in my laboratory is supported by grants from the Canadian Institutes of Health Research (CIHR), the Canadian Cancer Society (CCS), and the Howard Hughes Medical Institute (HHMI). I hold the Canada Research Chair in Signaling in the Immune System and am an HHMI International Scholar.

\section{REFERENCES}

Bleharski JR, Niazi KR, Sieling PA, Cheng G, Modlin RL. 2001. Signaling lymphocytic activation molecule is expressed on CD40 ligand-activated dendritic cells and directly augments production of inflammatory cytokines. J Immunol 167: 3174-3181.

Bloch-Queyrat C, Fondaneche MC, Chen R, Yin L, Relouzat F, Veillette A, Fischer A, Latour S. 2005. Regulation of natural cytotoxicity by the adaptor SAP and the Src-related kinase Fyn. J Exp Med 202: 181-192.

Bottino C, Augugliaro R, Castriconi R, Nanni M, Biassoni R, Moretta L, Moretta A. 2000. Analysis of the molecular mechanism involved in 2B4-mediated NK cell activation: Evidence that human 2B4 is physically and functionally associated with the linker for activation of T cells. Eur J Immunol 30: 3718-3722.

Bottino C, Falco M, Parolini S, Marcenaro E, Augugliaro R, Sivori S, Landi E, Biassoni R, Notarangelo LD, Moretta L, et al. 2001. NTB-A [correction of GNTB-A], a novel SH2D1A-associated surface molecule contributing to the inability of natural killer cells to kill Epstein-Barr virus-infected B cells in X-linked lymphoproliferative disease. J Exp Med 194: 235-246.

Bouchon A, Cella M, Grierson HL, Cohen JI, Colonna M. 2001. Cutting edge: Activation of NK cell-mediated cytotoxicity by a SAP-independent receptor of the CD2 family. J Immunol 167: 5517-5521.

Brown MH, Boles K, van der Merwe PA, Kumar V, Mathew PA, Barclay AN. 1998. 2B4, the natural killer and T cell immunoglobulin superfamily surface protein, is a ligand for CD48. J Exp Med 188: 2083-2090.
Calpe S, Erdos E, Liao G, Wang N, Rietdijk S, Simarro M, Scholtz B, Mooney J, Lee CH, Shin MS, et al. 2006. Identification and characterization of two related murine genes, Eat2a and Eat2b, encoding single SH2-domain adapters. Immunogenetics 58: 15-25.

Cambier JC, Pleiman CM, Clark MR. 1994. Signal transduction by the B cell antigen receptor and its coreceptors. Annu Rev Immunol 12: 457-486.

Cannons JL, Yu LJ, Hill B, Mijares LA, Dombroski D, Nichols KE, Antonellis A, Koretzky GA, Gardner K, Schwartzberg PL. 2004. SAP regulates T(H)2 differentiation and PKC-theta-mediated activation of NF-kappaB1. Immunity 21: 693-706.

Cannons JL, Yu LJ, Jankovic D, Crotty S, Horai R, Kirby M, Anderson S, Cheever AW, Sher A, Schwartzberg PL. 2006. SAP regulates T cell-mediated help for humoral immunity by a mechanism distinct from cytokine regulation. J Exp Med 203: 1551-1565.

Cao E, Ramagopal UA, Fedorov A, Fedorov E, Yan Q, Lary JW, Cole JL, Nathenson SG, Almo SC. 2006. NTB-A receptor crystal structure: Insights into homophilic interactions in the signaling lymphocytic activation molecule receptor family. Immunity 25: 559-570.

Castro AG, Hauser TM, Cocks BG, Abrams J, Zurawski S, Churakova T, Zonin F, Robinson D, Tangye SG, Aversa G, et al. 1999. Molecular and functional characterization of mouse signaling lymphocytic activation molecule (SLAM): Differential expression and responsiveness in Th1 and Th2 cells. J Immunol 163: 5860-5870.

Chan B, Lanyi A, Song HK, Griesbach J, Simarro-Grande M, Poy F, Howie D, Sumegi J, Terhorst C, Eck MJ. 2003. SAP couples Fyn to SLAM immune receptors. Nat Cell Biol 5: $155-160$.

Chen G, Tai AK, Lin M, Chang F, Terhorst C, Huber BT. 2005. Signaling lymphocyte activation moleculeassociated protein is a negative regulator of the CD8 T cell response in mice. J Immunol 175: 2212-2218.

Chen G, Tai AK, Lin M, Chang F, Terhorst C, Huber BT. 2007. Increased proliferation of CD8 $+\mathrm{T}$ cells in SAPdeficient mice is associated with impaired activationinduced cell death. Eur J Immunol 37: 663-674.

Chung B, Aoukaty A, Dutz J, Terhorst C, Tan R. 2005. Signaling lymphocytic activation molecule-associated protein controls NKT cell functions. J Immunol 174: 3153-3157.

Clarkson NG, Brown MH. 2009. Inhibition and activation by CD244 depends on CD2 and phospholipase C- $\gamma 1$. J Biol Chem 284: 24725-24734.

Cocks BG, Chang CC, Carballido JM, Yssel H, de Vries JE, Aversa G. 1995. A novel receptor involved in T-cell activation. Nature 376: 260-263.

Coffey AJ, Brooksbank RA, Brandau O, Oohashi T, Howell GR, Bye JM, Cahn AP, Durham J, Heath P, Wray P, et al. 1998. Host response to EBV infection in X-linked lymphoproliferative disease results from mutations in an SH2-domain encoding gene. Nat Genet 20: 129-135.

Cruz-Munoz ME, Dong Z, Shi X, Zhang S, Veillette A. 2009. Influence of CRACC, a SLAM family receptor coupled to the adaptor EAT-2, on natural killer cell function. Nat Immunol 10: 297-305.

Cunninghame Graham DS, Vyse TJ, Fortin PR, Montpetit A, Cai YC, Lim S, McKenzie T, Farwell L, Rhodes B, 
A. Veillette

Chad L, et al. 2008. Association of LY9 in UK and Canadian SLE families. Genes Immun 9: 93-102.

Davidson D, Shi X, Zhang S, Wang H, Nemer M, Ono N, Ohno S, Yanagi Y, Veillette A. 2004. Genetic evidence linking SAP, the X-linked lymphoproliferative gene product, to Src-related kinase FynT in $\mathrm{T}(\mathrm{H}) 2$ cytokine regulation. Immunity 21: 707-717.

Dong Z, Cruz-Munoz M, Zhong MC, Chen R, Latour S, Veillette A. 2009. Essential role of SAP family adaptors in natural killer cell surveillance of hematopoietic cells. Nat Immunol 10: 973-980.

Garni-Wagner BA, Purohit A, Mathew PA, Bennett M, Kumar V. 1993. A novel function-associated molecule related to non-MHC-restricted cytotoxicity mediated by activated natural killer cells and T cells. J Immunol 151: $60-70$.

Graham DB, Bell MP, McCausland MM, Huntoon CJ, van Deursen J, Faubion WA, Crotty S, McKean DJ. 2006. Ly9 (CD229)-Deficient Mice Exhibit T Cell Defects yet Do Not Share Several Phenotypic Characteristics Associated with SLAM- and SAP-Deficient Mice. J Immunol 176: $291-300$.

Griewank K, Borowski C, Rietdijk S, Wang N, Julien A, Wei DG, Mamchak AA, Terhorst C, Bendelac A. 2007. Homotypic interactions mediated by slamf1 and slamf6 receptors control NKT cell lineage development. Immunity 27: $751-762$.

Gu C, Tangye SG, Sun X, Luo Y, Lin Z, Wu J. 2006. The Xlinked lymphoproliferative disease gene product SAP associates with PAK-interacting exchange factor and participates in T cell activation. Proc Natl Acad Sci 103: 14447-14452.

Henning G, Kraft MS, Derfuss T, Pirzer R, Saint-Basile G, Aversa G, Fleckenstein B, Meinl E. 2001. Signaling lymphocytic activation molecule (SLAM) regulates T cellular cytotoxicity. Eur J Immunol 31: 2741-2750.

Howie D, Laroux FS, Morra M, Satoskar AR, Rosas LE, Faubion WA, Julien A, Rietdijk S, Coyle AJ, Fraser C et al 2005. Cutting Edge: The SLAM Family Receptor Ly108 Controls T Cell and Neutrophil Functions. J Immunol 174: $5931-5935$.

Huck K, Feyen O, Niehues T, Ruschendorf F, Hubner N, Laws HJ, Telieps T, Knapp S, Wacker HH, Meindl A, et al. 2009. Girls homozygous for an IL-2-inducible T cell kinase mutation that leads to protein deficiency develop fatal EBV-associated lymphoproliferation. J Clin Invest 119: $1350-1358$

Jordan MA, Fletcher JM, Pellicci D, Baxter AG. 2007. Slamf1, the NKT cell control gene Nkt1. J Immunol 178: $1618-1627$.

Kruse M, Meinl E, Henning G, Kuhnt C, Berchtold S, Berger T, Schuler G, Steinkasserer A. 2001. Signaling lymphocytic activation molecule is expressed on mature cd83(+) dendritic cells and is up-regulated by il- $1 \beta . J$ Immunol 167: 1989-1995.

Kumar KR, Li L, Yan M, Bhaskarabhatla M, Mobley AB, Nguyen C, Mooney JM, Schatzle JD, Wakeland EK, Mohan C. 2006. Regulation of B cell tolerance by the lupus susceptibility gene Ly108. Science 312: 1665-1669.

Latchman Y, McKay PF, Reiser H. 1998. Identification of the 2B4 molecule as a counter-receptor for CD48. J Immunol 161: $5809-5812$.
Latour S, Gish G, Helgason CD, Humphries RK, Pawson T, Veillette A. 2001. Regulation of SLAM-mediated signal transduction by SAP, the X-linked lymphoproliferative gene product. Nat Immunol 2: 681-690.

Latour S, Roncagalli R, Chen R, Bakinowski M, Shi X, Schwartzberg PL, Davidson D, Veillette A. 2003. Binding of SAP SH2 domain to FynT SH3 domain reveals a novel mechanism of receptor signalling in immune regulation. Nat Cell Biol 5: 149-154.

Lee KM, McNerney ME, Stepp SE, Mathew PA, Schatzle JD, Bennett M, Kumar V. 2004. 2B4 Acts As a Non-Major Histocompatibility Complex Binding Inhibitory Receptor on Mouse Natural Killer Cells. J Exp Med 199: $1245-1254$.

Li C, Schibli D, Li SS. 2009. The XLP syndrome protein SAP interacts with $\mathrm{SH} 3$ proteins to regulate $\mathrm{T}$ cell signaling and proliferation. Cell Signal 21: 111-119.

Li C, Chung B, Tao J, Iosef C, Aoukaty A, Wang Y, Tan R, Li SS. 2008. The X-linked lymphoproliferative syndrome gene product SAP regulates B cell function through the FcyRIIB receptor. Cell Signal 20: 1960-1967.

Ma CS, Nichols KE, Tangye SG. 2007. Regulation of cellular and humoral immune responses by the SLAM and SAP families of molecules. Annu Rev Immunol 25: 337-379.

McNerney ME, Guzior D, Kumar V. 2005. 2B4 (CD244)CD48 interactions provide a novel MHC class I-independent system for NK-cell self-tolerance in mice. Blood 106: 1337-1340.

Mooney JM, Klem J, Wulfing C, Mijares LA, Schwartzberg PL, Bennett M, Schatzle JD. 2004. The murine NK receptor 2B4 (CD244) exhibits inhibitory function independent of signaling lymphocytic activation molecule-associated protein expression. J Immunol 173: 3953-3961.

Morra M, Howie D, Grande MS, Sayos J, Wang N, Wu C, Engel P, Terhorst C. 2001. X-linked lymphoproliferative disease: A progressive immunodeficiency. Annu Rev Immunol 19: 657-682.

Nakajima H, Cella M, Langen H, Friedlein A, Colonna M. 1999. Activating interactions in human NK cell recognition: The role of 2B4-CD48. Eur J Immunol 29: 1676-1683.

Nanda N, Andre P, Bao M, Clauser K, Deguzman F, Howie D, Conley PB, Terhorst C, Phillips DR. 2005. Platelet aggregation induces platelet aggregate stability via SLAM family receptor signaling. Blood 106: 3028-3034.

Nichols KE, Harkin DP, Levitz S, Krainer M, Kolquist KA, Genovese C, Bernard A, Ferguson M, Zuo L, Snyder E, et al. 1998. Inactivating mutations in an $\mathrm{SH} 2$ domainencoding gene in X-linked lymphoproliferative syndrome. Proc Natl Acad Sci 95: 13765-13770.

Nichols KE, Hom J, Gong SY, Ganguly A, Ma CS, Cannons JL, Tangye SG, Schwartzberg PL, Koretzky GA, Stein PL. 2005. Regulation of NKT cell development by SAP, the protein defective in XLP. Nat Med 11: 340-345.

Nunez-Cruz S, Yeo WC, Rothman J, Ojha P, Bassiri H, Juntilla M, Davidson D, Veillette A, Koretzky GA, Nichols KE. 2008. Differential requirement for the SAP-Fyn interaction during NK T cell development and function. J Immunol 181: 2311-2320.

Oliver-Vila I, Saborit-Villarroya I, Engel P, Martin M. 2008. The leukocyte receptor CD84 inhibits Fc epsilon 
RI-mediated signaling through homophilic interaction in transfected RBL-2H3 cells. Mol Immunol 45: 2138 2149.

Ostrakhovitch EA, Wang Y, Li SS. 2009. SAP binds to CD22 and regulates $B$ cell inhibitory signaling and calcium flux. Cell Signal 21: 540-550.

Pasquier B, Yin L, Fondaneche MC, Relouzat F, BlochQueyrat C, Lambert N, Fischer A, Saint-Basile G, Latour S. 2005. Defective NKT cell development in mice and humans lacking the adapter SAP, the X-linked lymphoproliferative syndrome gene product. $J$ Exp Med 201: 695-701.

Qi H, Cannons JL, Klauschen F, Schwartzberg PL, Germain RN. 2008. SAP-controlled T-B cell interactions underlie germinal centre formation. Nature 455: 764-769.

Rethi B, Gogolak P, Szatmari I, Veres A, Erdos E, Nagy L, Rajnavolgyi E, Terhorst C, Lanyi A. 2006. SLAM/SLAM interactions inhibit CD40-induced production of inflammatory cytokines in monocyte-derived dendritic cells. Blood 107: 2821-2829.

Rigaud S, Fondaneche MC, Lambert N, Pasquier B, Mateo V, Soulas P, Galicier L, Le DF, Rieux-Laucat F, Revy P, et al. 2006. XIAP deficiency in humans causes an X-linked lymphoproliferative syndrome. Nature 444: 110-114.

Roncagalli R, Taylor JE, Zhang S, Shi X, Chen R, CruzMunoz ME, Yin L, Latour S, Veillette A. 2005. Negative regulation of natural killer cell function by EAT-2, a SAP-related adaptor. Nat Immunol 6: 1002-1010.

Sayos J, Wu C, Morra M, Wang N, Zhang X, Allen D, van Schaik S, Notarangelo L, Geha R, Roncarolo MG, et al. 1998. The X-linked lymphoproliferative-disease gene product SAP regulates signals induced through the co-receptor SLAM. Nature 395: 462-469.

Schwartzberg PL, Mueller KL, Qi H, Cannons JL. 2009. SLAM receptors and SAP influence lymphocyte interactions, development and function. Nat Rev Immunol 9: 39-46.

Sidorenko SP, Clark EA. 1993. Characterization of a cell surface glycoprotein IPO-3, expressed on activated human B and T lymphocytes. J Immunol 151: 4614-4624.

Sivori S, Falco M, Marcenaro E, Parolini S, Biassoni R, Bottino C, Moretta L, Moretta A. 2002. Early expression of triggering receptors and regulatory role of 2B4 in human natural killer cell precursors undergoing in vitro differentiation. Proc Natl Acad Sci 99: 4526-4531.

Suzuki A, Yamada R, Kochi Y, Sawada T, Okada Y, Matsuda K, Kamatani Y, Mori M, Shimane K, Hirabayashi Y, et al. 2008. Functional SNPs in CD244 increase the risk of rheumatoid arthritis in a Japanese population. Nat Genet 40: $1224-1229$.

Tassi I, Colonna M. 2005. The cytotoxicity receptor CRACC (CS-1) recruits EAT-2 and activates the PI3K and phospholipase $\mathrm{C} \gamma$ signaling pathways in human NK cells. J Immunol 175: 7996-8002.

Tatsuo H, Ono N, Tanaka K, Yanagi Y. 2000. SLAM (CDw150) is a cellular receptor for measles virus. Nature 406: 893-897.

Vacca P, Pietra G, Falco M, Romeo E, Bottino C, Bellora F, Prefumo F, Fulcheri E, Venturini PL, Costa M, et al. 2006. Analysis of natural killer cells isolated from human decidua: Evidence that 2B4 (CD244) functions as an inhibitory receptor and blocks NK-cell function. Blood 108: $4078-4085$.

Vaidya SV, Stepp SE, McNerney ME, Lee JK, Bennett M, Lee KM, Stewart CL, Kumar V, Mathew PA. 2005. Targeted Disruption of the 2B4 Gene in Mice Reveals an In Vivo Role of 2B4 (CD244) in the Rejection of B16 Melanoma Cells. J Immunol 174: 800-807.

Veillette A. 2006b. Immune regulation by SLAM family receptors and SAP-related adaptors. Nat Rev Immunol 6: $56-66$.

Veillette A. 2006a. NK cell regulation by SLAM family receptors and SAP-related adapters. Immunol Rev 214: 22-34.

Veillette A, Cruz-Munoz ME, Zhong MC. 2006. SLAM family receptors and SAP-related adaptors: Matters arising. Trends Immunol 27: 228-234.

Veillette A, Dong Z, Latour S. 2007. Consequence of the SLAM-SAP Signaling Pathway in Innate-like and Conventional Lymphocytes. Immunity 27: 698-710.

Veillette A, Dong Z, Pérez-Quintero L-A, Zhong MC, CruzMunoz M. 2009. Importance and mechanism of 'switch' function of SAP family adapters. Immunol Rev 232: 229-239.

Veillette A, Zhang S, Shi X, Dong Z, Davidson D, Zhong MC. 2008. SAP expression in T cells, not in B cells, is required for humoral immunity. Proc Natl Acad Sci 105: $1273-1278$.

Velikovsky CA, Deng L, Chlewicki LK, Fernandez MM, Kumar V, Mariuzza RA. 2007. Structure of Natural Killer Cell Receptor 2B4 (CD244) Bound to its Ligand, CD48. Immunity 27: 572-584.

Wandstrat AE, Nguyen C, Limaye N, Chan AY, Subramanian S, Tian XH, Yim YS, Pertsemlidis A, Garner HRJr, Morel L et al. 2004. Association of extensive polymorphisms in the SLAM/CD2 gene cluster with murine lupus. Immunity 21: 769-780.

Wang N, Satoskar A, Faubion W, Howie D, Okamoto S, Feske S, Gullo C, Clarke K, Sosa MR, Sharpe AH, et al. 2004. The Cell Surface Receptor SLAM Controls T Cell and Macrophage Functions. J Exp Med 199: 1255-1264.

Yan Q, Malashkevich VN, Fedorov A, Fedorov E, Cao E, Lary JW, Cole JL, Nathenson SG, Almor SC. 2007. Structure of CD84 provides insight into SLAM family function. Proc Natl Acad Sci 104: 10583-10588. 


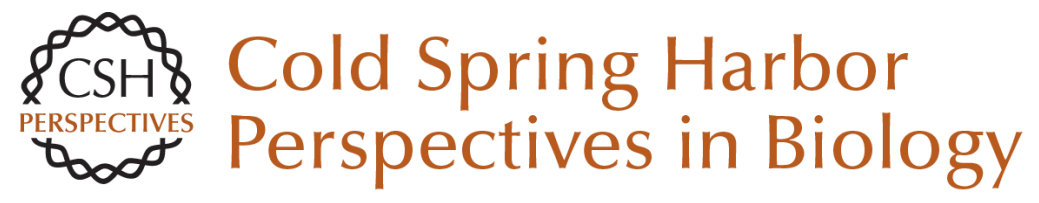

\section{SLAM-Family Receptors: Immune Regulators with or without SAP-Family Adaptors}

André Veillette

Cold Spring Harb Perspect Biol 2010; doi: 10.1101/cshperspect.a002469 originally published online February 17, 2010

Subject Collection Immunoreceptor Signaling

The Coordination of T-cell Function by

Serine/Threonine Kinases

David Finlay and Doreen Cantrell

ITAM-mediated Signaling by the T-Cell Antigen

Receptor

Paul E. Love and Sandra M. Hayes

Coordination of Receptor Signaling in Multiple Hematopoietic Cell Lineages by the Adaptor

Protein SLP-76

Martha S. Jordan and Gary A. Koretzky

The Cytoskeleton Coordinates the Early Events of B-cell Activation

Naomi E. Harwood and Facundo D. Batista

An Enigmatic Tail of CD28 Signaling

Jonathan S. Boomer and Jonathan M. Green

Mediation of T-Cell Activation by Actin

Meshworks

Peter Beemiller and Matthew F. Krummel
Perspectives for Computer Modeling in the Study

of T Cell Activation Jesse Coward, Ronald N. Germain and Grégoire Altan-Bonnet

Structural Biology of the T-cell Receptor: Insights into Receptor Assembly, Ligand Recognition, and Initiation of Signaling

Kai W. Wucherpfennig, Etienne Gagnon, Melissa J. Call, et al.

Src-family and Syk Kinases in Activating and Inhibitory Pathways in Innate Immune Cells:

Signaling Cross Talk Clifford A. Lowell

The LAT Story: A Tale of Cooperativity, Coordination, and Choreography Lakshmi Balagopalan, Nathan P. Coussens, Eilon Sherman, et al.

Antigen Receptor Signaling to NF- $\mathrm{KB}$ via

CARMA1, BCL10, and MALT1 Margot Thome, Jean Enno Charton, Christiane Pelzer, et al.

It's All About Change: The Antigen-driven Initiation of B-Cell Receptor Signaling Wanli Liu, Hae Won Sohn, Pavel Tolar, et al.

For additional articles in this collection, see http://cshperspectives.cshlp.org/cgi/collection/

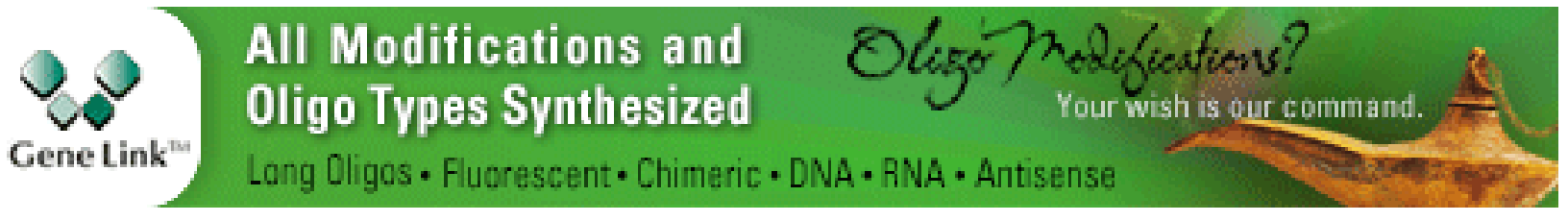

Copyright @ 2010 Cold Spring Harbor Laboratory Press; all rights reserved 
T-Cell Signaling Regulated by the Tec Family

Kinase, Itk

Amy H. Andreotti, Pamela L. Schwartzberg, Raji E. Joseph, et al.

Lipid Signaling in T-Cell Development and

Function

Yina H. Huang and Karsten Sauer
ZAP-70: An Essential Kinase in T-cell Signaling Haopeng Wang, Theresa A. Kadlecek, Byron B. Au-Yeung, et al.

Understanding the Structure and Function of the Immunological Synapse

Michael L. Dustin, Arup K. Chakraborty and Andrey S. Shaw

For additional articles in this collection, see http://cshperspectives.cshlp.org/cgi/collection/

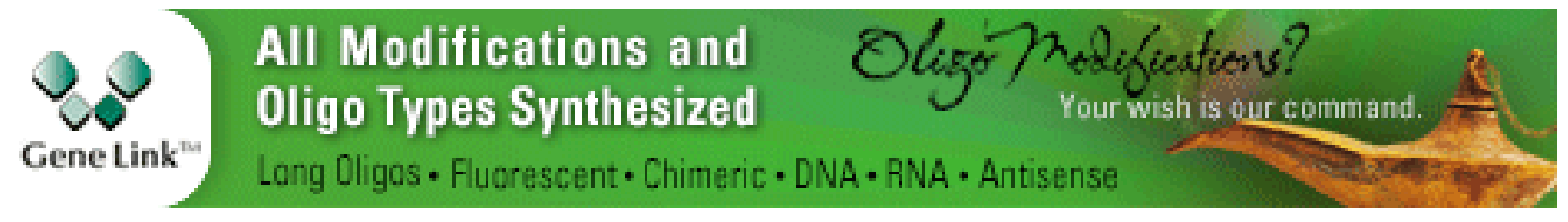

Copyright @ 2010 Cold Spring Harbor Laboratory Press; all rights reserved 